\title{
Marxismo e historia intelectual en la Argentina (y más allá): notas para una investigación
}

\author{
Omar Acha \\ Consejo Nacional de Investigaciones Científicas y Técnicas - Universidad de Buenos Aires \\ Centro de Investigaciones Filosóficas \\ omaracha@gmail.com
}

Titulo: Marxism and Intellectual History in Argentina (and Beyond): Notes for an Investigation

\begin{abstract}
Resumen: La trayectoria de la historia intelectual en la Argentina de los últimos treinta años participa de un proceso correlativo a la crisis del marxismo en términos culturales, académicos y políticos. Ese tránsito historiográfico encuentra semejanzas con trayectorias historiográficas occidentales, pero revela también particularidades nacionales. En la Argentina, la práctica y la teoría de la historia intelectual tuvieron una menor distancia con el marxismo, cuyas peculiaridades son aquí analizadas. La reinterpretación de la teoría crítica marxista de las últimas décadas sitúa en otro marco conceptual -prolongando una hipótesis de José Sazbón formulada en 1997- la posibilidad de que el marxismo intervenga en las proyecciones de investigación de la historia intelectual. Este trabajo interrelaciona historia y teoría enfocando en los derroteros historiográficos argentinos como índices de debates más amplios.
\end{abstract}

Palabras clave: marxismo - historia intelectual - teoría crítica - historiografia argentina

Abstract: The trajectory of intellectual history in Argentina in the last thirty
years participates in a process correlative to the crisis of Marxism in cultural,
academic and political terms. This historiographic transit finds similarities with
western historiographic trajectories, but it also reveals national peculiarities. In
Argentina, the practice and theory of intellectual history never interrumped a
relationship with Marxism, which peculiarities are analyzed here. The reinterpre-
tation of Marxist critical theory of the last decades places in another conceptual 
framework the possibility -prolonging a hyphotesis raised by José Sazbón in 1997- that Marxism intervenes in the research projections of intellectual history. This work interrelates history and theory, focusing on Argentine historiographic paths as indexes of broader debates.

Keywords: Marxism - Intellectual History - Critical Theory - Argentine Historiography

Recepción: 28 de diciembre de 2020. Aceptación: 15 de febrero de 2021

$* * *$

\section{Marxismo e historia intelectual: ¿divorcio por incompatibilidad de caracteres? $^{1}$}

La conexión conceptual entre la disciplina de la historia intelectual y el marxismo es problemática. La búsqueda en Google Scholar o en JSTOR de referencias bibliográficas con los términos en inglés de "marxismo" e "historia intelectual" es infructuosa. Nada modifica introducir los mismos conceptos en otras lenguas o variaciones booleanas en las palabras-clave del searching. Lo que aparece es el marxismo en tanto tema de la historia intelectual, como en los libros de Horacio Tarcus sobre el marxismo en la Argentina o el de Carlos Illades sobre el mismo tópico en México. En este artículo estudiaré un asunto diferente: la eventualidad de un enfoque marxista en historia intelectual.

La ajenidad entre marxismo e historia intelectual está lejos de ser circunstancial. Existen al menos dos razones para esa exterioridad. En primer lugar, dicha especialidad historiográfica, distinguible de una más antigua "historia de las ideas", conquista un mayor reconocimiento en contemporaneidad con el cuestionamiento de la historia económica y social con la cual la historiografia marxista supo identificarse. En segundo lugar, los programas de investigación de historia intelectual suelen presuponer una crítica del marxismo o de un conjunto de rasgos explicativos atribuidos al marxismo. Resultante de ello es que un libro destinado a trazar un "estado del arte" de la historia intelectual como el de François Dosse (2007), puede prescindir de toda referencia significativa a la teoria e historiografia marxistas.

La historia intelectual como especialidad historiográfica en la investigación de base universitaria es relativamente reciente. Participa de una mutación paradigmática en los estudios históricos que acompañó al agotamiento de la golden age de la sociedad capitalista entre 1945 y

1. Agradezco los comentarios de Valeria A. Caruso, Hernán Camarero y Carlos M. Herrera. Los errores persistentes son de mi exclusiva responsabilidad. 
1975, lapso durante el cual la historia social y económica conquistó un sitial preponderante. Considerado desde el punto de vista historiográfico del siglo XX, es posible datar el parteaguas de 1929 que hizo saliente la relación economía/sociedad como un problema. El surgimiento de revistas especializadas con capacidad de durar es un indice de esta relevancia. En 1927 se funda la Economic History Reviewy en 1929 aparece Annales d'Histoire Économique et Sociale. Como suele ocurrir, una cronología más precisa introduce complicaciones a un orden estilizado de segmentaciones historiográficas: el Journal of the History of Ideas comenzó a publicarse en 1940 y constituyó una referencia insoslayable en la materia pero, justamente, allí encontró su frontera.

El año 1945 constituyó una divisoria secular que verificó un impulso extraordinario de la globalización regida por la expansión del capital. Incluso el socialismo burocrático de la Unión Soviética continuó con su modernización alternativa en competencia con la sociedad capitalista, pero siempre en un orden mundial regido por la valorización. La historia económica y social se hizo hegemónica. La historia de las ideas fue lateral a aquella hegemonía, aunque, como la historia política, continuó vigente en sectores de la historiografia. La historia "intelectual" no existía como tal. A pesar de que la expresión "historia intelectual" estaba presente en el conocido artículo de Arthur Lovejoy inaugural del Journal of the History of Ideas, y en 1951 John Higham mentaba su condición proteica en "The Rise of American Intellectual History", carecía del posterior alcance de delimitador disciplinar (Lovejoy, 1940; Higham, 1951).

Cuando Dominick LaCapra (n. 1939) convocó a un congreso en la Universidad de Cornell -reunido en 1980- para reflexionar sobre la situación de la historia intelectual, uno de sus principales argumentos consistió en señalar su subalternidad respecto de la historia social. Con algunas asincronías, en la historiografía argentina se verificó una cadencia similar.

Hace unos veinte años, el historiador José Carlos Chiaramonte (n. 1931) me relató que él como estudioso iniciado con sus Ensayos sobre la Ilustración argentina (1962), comenzó a ser mejor estimado en el gremio historiográfico cuando se dedicó a la historia económica y social resultante en su libro Nacionalismo y liberalismo económicos (1971). La historia de las ideas constituía un género secundario. No modifica la situación que algunos referentes de importancia como José Luis Romero y Tulio Halperin Donghi pudieran practicarla a su manera. Mientras tanto, diversas versiones del marxismo generaban usos en términos historiográficos por parte de nuevas camadas de investigadores en las décadas de 1960 y 1970. Para esas recientes promociones, las ideas, representaciones y conceptos, carecían de interés autónomo.

Desde los primeros años de la "transición democrática" posdictato- 
rial, una nueva generación de investigadores, incluso filiándose en la "renovación" posterior a 1955 y vigente hasta 1976, procuró actualizar el panorama historiográfico sin necesariamente extrañarse de la historia social, de las referencias de Annales o del marxismo (sobre todo el británico). Los debates históricos centrales de esos años, a saber, a propósito del gaucho en la campaña rioplatense del siglo XIX, respecto de la tesis del pluralismo cultural en las migraciones del periodo 1870-1930 y a propósito de los "sectores populares" versus la clase obrera del siglo $\mathrm{XX}$, aunque con aspiraciones innovadoras, pertenecian a un horizonte conceptual comunicable con los marcos analíticos previamente vigentes.

Si también en la Argentina el nombre de Michel Foucault se imponía como una cita cada vez menos soslayable en las introducciones de las tesis de posgrado, no solo en historia, su característico enfoque discursivo -más allá del concepto de dispositivo que raramente halló plasmación metódica- coexistió con preguntas sobre los contextos sociales del pensamiento y de las textualidades. Jamás se produjo un corte radical con la historia social en beneficio de un indeterminismo textualista, lingüístico o discursivo, a pesar de algunas evaluaciones apresuradas sobre "la moda del posmodernismo".

En verdad, también en lo que comenzaba a denominarse la new intellectual history en la historiografia del norte global, la transformación más relevante estaba in fieri hacia fines de la década de 1970, particularmente en lo tocante a la aproximación discursiva. Los elencos bibliográficos estaban en formación. En el hoy casi legendario volumen editado por LaCapra y Kaplan en 1982, Modern European Intellectual History. Reappraisals and New Perspectives, la centralidad reconocida al posestructualismo francés hacía innecesario apelar de manera consistente a la pragmática del lenguaje de la Escuela de Cambridge (Dunn, Pocock, Skinner). Empleando una desgastada dicotomía, el volumen se nutría más de la filosofia "continental" que de la batería "analítica" asociada al linguistic turn. Por otro lado, los efectos de la Begriffsgeschichte, ya consolidada en la historiografia germanoparlante, recién comenzaba a percibirse allende Alemania.

El libro de LaCapra y Kaplan contenía una dificultad constitutiva que presidía, con sus respectivos matices, las contribuciones de Roger Chartier y Martin Jay. Se trata de la dualidad entre lo que ingresa al ámbito de lo intelectual-discursivo y lo que, sin ser ajeno al mismo, involucra aspectos diferentes de la vida social. Las versiones sofisticadas de la historia intelectual suelen apelar al concepto de "práctica" para sustraerse al reproche habitual a la historia de las ideas como subsidiaria del platonismo, de presuponer un plano ideal ajeno a la realidad concreta. Sin embargo, las dificultades de la mencionada dualidad no cesan de reproducirse. La fórmula foucaultiana de "práctica discursi- 
va" o la austiniana de "fuerza ilocucionaria" reintroducen en su seno aquello que procuran neutralizar, esto es, el problema de los contextos tan evidente en la historia de las ideas.

Es así que en La arqueología del saber el concepto de "práctica no discursiva" es vacilante, y algo similar ocurre con el "contexto" en John Austin, tal como indicó con rigor Jacques Derrida en "Firma, acontecimiento, contexto". El debate entre Reinhart Koselleck y Hans-Georg Gadamer a propósito de la universalidad de la lingüísticidad hermenéutica redunda en la misma encrucijada teórica. Estas incertidumbres acompañan hasta hoy a la historia intelectual. La dificultad de coligar textos o representaciones y prácticas -precisamente aquello que la distinguiría de la "tradicional historia de las ideas"- constituye un problema inherente a la gramática de la historiografia intelectual.

Dicho esto, la particularidad argentina demanda reconocer las singularidades y temporalidades específicas de una investigación historiadora en reconstrucción tras la sangrienta dictadura militar concluida en 1983. Un volumen publicado a fines de la década de 1980, Historiografia argentina: 1958-1988, proporciona un itinerario de la historia de las ideas en la contribución del filósofo Arturo Roig (Hugo Biagini, otro cultor de la especialidad, se ocupó de las "ideas filosóficas"). La historia intelectual no constituía una rama autónoma. Roig mencionó al pasar la historia intelectual entre otras formulaciones próximas, así como subrayó la reciente importancia concedida a "las palabras" y al "discurso", aunque para su propio trabajo halló sede confortable en la legitimidad de la historia de las ideas. Por esos años, la historiadora social y política Hilda Sabato presentó en la revista Punto de Vista una actualización de las novedades sobre la intellectual history suscitadas por el volumen editado por LaCapra-Kaplan y La gran matanza de gatos de Robert Darnton. En su crónica, en la cual las preguntas de la historia social no eran irrelevantes, se subrayaban las incertidumbres de una apertura interesante.

Un diferendo local a propósito de este momento historiográfico asomó en la lectura que un historiador social como Juan Carlos Garavaglia (1944-2017) elaboró sobre el libro de Jorge Myers (n. 1961), Orden y virtud. El discurso republicano en el régimen rosista (1995). La intervención de Garavaglia expresó un desencuentro entre la historiografia económico-social y la "nueva" historia de las ideas que pronto sería "intelectual". Myers, quien como Elías Palti, a quien haré referencia pronto, había estudiado en la academia euroatlántica, introdujo una perspectiva novedosa ligada al estudio de los "lenguajes políticos" y el republicanismo. Garavaglia reprochó al enfoque de Myers el situarse en el plano discursivo y textual sin incorporar las condiciones reales de los debates "agraristas" del periodo rosista en el Río de la Plata (Garavaglia, 
1996). Según el crítico, Myers acudía a referencias más o menos plausibles de una tradición republicana de contornos imprecisos, forzando un desplazamiento metodológico desde otras historiografias mejor pertrechadas con conocimientos de la época. Sobre el Río de la Plata aún se desconocían demasiadas cosas del período rosista como para desentrañar adecuadamente el significado histórico de ciertos discursos, los que no podían ser estudiados solo en referencia a otros discursos.

Myers respondió al comentario de Garavaglia con aclaraciones sobre el objeto de su análisis. En esencia, puntualizó que en su libro había investigado "los lenguajes políticos, sus formas de producción y circulación, y sus usos, durante la época rosista" (Myers, 1996: 184). $\mathrm{El}$ aleccionamiento de Garavaglia expresaría una preferencia historiográfica respecto de la cual otras aproximaciones serian, lógicamente, secundarias o precarias. La pregunta de Myers no pretendia averiguar el "origen" de los discursos, fuera en otros discursos o en las disputas en torno a la producción agraria. Procuraba restituir el "sentido" que los hechos discursivos revelaban de la circulación del republicanismo en el periodo. El autor reaccionó a la reseña por algo más que una autodefensa: es que el reseñista asumía en su examen el gesto de una jerarquización historiográfica. Y debe admitirse que el señalamiento era apropiado: los comentarios sobre el mismo libro preparados por Tulio Halperin Donghi (Anuario del IEHS, 12, 1997) e Hilda Sabato (Revista de Ciencias Sociales, 3, 1995) ponderaron la conveniencia de ahondar las dimensiones prácticas prometidas pero no del todo exploradas por Myers, sin atribuirse la condescendencia historiográfica esgrimida por Garavaglia.

En efecto, no se verificó de manera general una actitud reactiva ante la naciente historia intelectual. Al respecto, la tarea historiadora e institucional del filósofo Oscar Terán (1938-2008) fue decisiva. Formado en una época en que todavía la historia de las ideas gozaba de cierto prestigio, acompañó la renovación de la especialidad y facilitó una metamorfosis de vocabulario. Tan importante como eso fue que acompañó la emergencia de una nueva generación historiográfica, munida de más recientes bibliografias, con la que hizo ingreso decidido a la historia intelectual tal como hoy la conocemos. ${ }^{2}$

Para Terán, como para su coetáneo Carlos Altamirano (n. 1939), el horizonte del "campo" en formación era heterogéneo, admitía matices

2. Tiene un lugar destacado en esa tarea la creación del Programa y luego Centro de Historia Intelectual en la Universidad Nacional de Quilmes, la publicación desde 1997 de Prismas. Revista de Historia Intelectual, y la aparición, coordinada por Carlos Altamirano, de los dos volúmenes de la Historia de los intelectuales en América Latina. Un análisis de la significación de este núcleo de investigación exigiría un estudio imposible de desarrollar aquí. 
y diferencias. No había una sola manera de aproximarse a la historia intelectual. Por ejemplo, en una nota de 1991, "Breve apología de la historia intelectual", Altamirano ponderó la publicación relativamente reciente de estudios como La tradición republicana de Natalio Botana, Ingenieros: pensar la nación de Terán, José Hernández y sus mundos de Halperin, y dos allegados desde la crítica literaria con interés histórico, Una modernidad periférica de Beatriz Sarlo y El criollismo en la formación de la Argentina moderna de Adolfo Prieto. La cuestión de una "modernidad" peculiar era un hilo conductor posible que permitia engarzar todos esos estudios (Altamirano, 1990-1991). Los nombres de John Pocock o Koselleck eran ajenos al tenor conceptual de esos trabajos. La excepción fue el libro de Botana, donde se citaba a Skinner y Pocock, aunque su enfoque tradicional identificaba modelos ideales en Sarmiento, "la república de la virtud", y en Alberdi, "la república del interés".

Es imposible hacer aquí justicia a la complejidad de Terán como historiador. Me interesa sintetizar su significación historiográfica, a riesgo de simplificar, porque muestra una cuestión atinente a la materia del presente artículo (un análisis detallado en Acha, 2017). Para el Terán retornado del exilio mexicano, la Argentina de los años 80 implicó una revisión profunda de sus previos convencimientos marxistas, y el análisis histórico de las ideas de izquierda constituyó una de sus preocupaciones perdurables. Las ideas de la razón eran ambivalentes, pues junto a sus potencias emancipatorias podían soñar con monstruos y suscitar pesadillas tiránicas. Era lo que según Terán había acontecido con el marxismo durante el tramo en que se crearon las condiciones de una licuación del pensamiento crítico en la "crítica de las armas": Nuestros años sesentas. La formación de la nueva izquierda intelectual argentina, 1956-1966, es un clásico de nuestra historiografia (Terán, 1991). Es también uno de los mayores documentos producidos en la Argentina a propósito de la figura de la crisis del marxismo.

El objeto y el autor, el pasado y el presente, se confundian en una investigación que problematizaba las derivas políticas del marxismo con sus varias fusiones (por ejemplo, con el nacionalismo) junto a un mandato que no olvidaba pero mudaba con decisión el terreno en que situaba la perspectiva de análisis. Lo importante es que si el mensaje de Nuestros años sesentas era que tras la historia vivida no se podía ser marxista, el posmarxismo de Terán continuaba reflexionando sobre la historia del marxismo. Por eso la historia de las ideas constituia un dispositivo menos complaciente que las memorias heridas o épicas para revisar el pasado. Y si el marxismo era cuestionado por su incapacidad para pensar una política democrática, también lo era como guía metódica para estudiar la historia de las ideas, fuera que primara un sentido objetivo de la Historia, una reducción clasista del pensamiento 
o un aplastamiento economicista de las prácticas intelectuales. En su singular posmarxismo, Terán acuñó una perspectiva que sin necesariamente abandonar conceptos marxistas de validez particular, fuese pluralista y versátil para apelar a otros archivos conceptuales acordes con las exigencias de la investigación concreta.

La crisis del marxismo -aunque supeditada a una inquisición mayor ligada a la identidad latinoamericana- es presupuesta en otra línea de la historia de las ideas que aquí no será examinada, pues desarrolla una aproximación que dialoga con la filosofia, el ensayo y los estudios culturales antes que con la historiografia. Hace de la crítica del eurocentrismo un momento central de una redefinición de la historia de las ideas, y el marxismo en ese razonamiento sería europeísta (a pesar de Fanon y Mariátegui). Me refiero a la filosofia latinoamericana de las ideas y a la "opción decolonial" desarrolladas desde una reconversión de la línea interpretativa de Leopoldo Zea y Arturo Roig, reinterpretada tras las intervenciones criticas de Walter Mignolo y Enrique Dussel. Afincadas en nutridos grupos de investigación con sede en las universidades de Córdoba, Cuyo y Lanús, merecerían un examen autónomo. Regreso entonces al surgimiento de la historia intelectual entre los escombros de una reciente crisis del marxismo.

En lo tocante a las nuevas promociones historiadoras de los años 90, su espacio de experiencia fue muy otro que el de Terán. La condición posmarxista era una premisa o un proceso en curso. Para algunos de sus integrantes no constituía un problema relevante. Para otros, la deconstrucción del marxismo fue una y la misma cosa que la edificación de un programa de historia intelectual. Para muy pocos fue también una posibilidad de disputar un lugar para el marxismo entre las prácticas historiográficas. Sin embargo, nuevamente naufraga la miseria de las periodizaciones. En este lugar, aquella de las segmentaciones generacionales, pues un ensayo de reconexión entre teoría crítica marxista e historia intelectual fue esbozada por un integrante de la generación de los años 60, el filósofo José Sazbón (1937-2008). Antes de visitar la propuesta de Sazbón necesito dar un rodeo en torno a la problemática contemporánea del marxismo como teoría crítica. Es que si fuera inviable conciliar alguna versión de la teoría marxista con la historia intelectual, las disquisiciones ulteriores serian ociosas. Admito que el siguiente rodeo es también el sintoma de una dificultad en el marxismo existente antes y después del giro lingüístico.

\section{Las transformaciones del marxismo y la historia intelectual}

Las décadas que verificaron la declinación relativa de la historia socioeconómica y la emergente primacía de las historiografias política y 
cultural, con las cuales la historia intelectual estuvo emparentada, fueron paradójicas. Lo paradójico consiste en lo siguiente: al mismo tiempo que se imponía -con el parteaguas de la caída del "socialismo realmente existente" entre 1989 y 1991- un irrefrenable viraje posmarxista en el escenario intelectual y académico, la dominación global de la sociedad capitalista como un todo planetario se tornó el dato central de nuestra época. Dicho en otras palabras, cuando se consolidaba la pertinencia del marxismo como teoría crítica de una lógica global objetiva, el marxismo experimentaba un declive en el ámbito de las humanidades y las ciencias sociales.

Tal mutación sería inexplicable desde una inducción que acumulara defecciones antiguas y cegueras recientes asumidas como efectos "ideológicos". Es razonablemente convincente, según pretende Perry Anderson, la evaluación por Fredric Jameson del "posmodernismo" como la "lógica cultural" del "capitalismo avanzado". Los planteos posestructuralistas y posfundacionalistas corresponden miméticamente, en el plano de la teoría, con las formas de acumulación capitalista posfordista o neoliberal: plurales, fluidas, diseminantes, deconstructivas, etcétera. Por eso pueden describir rasgos de la realidad global pero no explicar su lógica sistémica. De ello no se sigue, sin embargo, que el marxismo sea aún esclarecedor.

Decir "marxismo" implica abrir una Caja de Pandora. Marxismos hubo muchos, y es intrinsecamente discutible que se puedan encauzar en un Sistema gracias a la lectura de "lo que Marx efectivamente dijo". Marx mismo es un archivo inconcluso y contradictorio de textos, fragmentos, cartas, notas, esbozos, sobre los que no podemos hacer otra cosa que interpretar. Con eso no sugiero que nos hallamos en un laberinto de arbitrariedades dilemáticas, sino más bien ante responsabilidades teóricas e interpretativas.

Debe admitirse que entre los marxismos desarrollados por varias generaciones de intelectuales y activistas hubo algunos que lo tornan incompatible con cualquier proyecto sofisticado de historia intelectual. Me refiero a un presunto realismo materialista que hace de lo económico o lo social un fundamento respecto del cual lo cultural o discursivo sería derivativo. Atribuir eficacia a las prácticas discursivas, a las configuraciones textuales o a las formas simbólicas constituye, para esa interpretación del marxismo, un idealismo. Por supuesto, las formulaciones teóricas no se reflejaron mecánicamente en la investigación marxista. Se produjeron excelentes estudios legibles retroactivamente como historia intelectual: la Historia social de la literatura y el arte de Arnold Hauser, El dios oculto de Lucien Goldmann o la Obra de los pasajes de Walter Benjamin.

Lo que quiero elaborar aquí de una manera sucinta es una reinter- 
pretación del marxismo, rastreable hasta los años 60 del siglo pasado, donde se pueden hallar elementos para una discusión, a primera vista implausible, del nexo con la historia intelectual.

Me refiero a la línea de trabajo abierta en la estela de la Dialéctica negativa de Theodor Adorno. ${ }^{3}$ El punto de partida consiste en leer en el Marx posterior al reinicio de sus investigaciones de una crítica de la economía política en 1850, no una teoría positiva de la determinación válida como explicación general de la historia, sino una teoría crítica de la lógica social y contradictoria específica de la sociedad capitalista. La totalidad no es en ese argumento un ideal al que regresar, como aparecía en György Lukács y era subyacente a la utopía de un comunismo de la sociedad reconciliada consigo misma. El todo capitalista compone una formación contradictoria generada por la emergencia de un principio social de mediación: el trabajo abstracto generador de un automovimiento enajenado, el valor que se valoriza a través de la apropiación de plusvalor, fenoménicamente perceptible en la forma dineraria y en la extensión universalizante del mercado mundial.

Esa lógica no es exclusivamente económica: se verifica en todos los planos de la experiencia, asumiendo configuraciones concretas irreductibles a una sola forma de acumulación o explotación, incluidas aquellas mediaciones de la vida "privada" y de las "ideas". De hecho, un principio incorporado en la acumulación capitalista, el desarrollo de la ciencia y de la tecnología orientado a la amplificación del plusvalor relativo, es el índice de una materialidad inadecuadamente opuesta al idealismo. El punto de apoyo arquimedeano de la plasmación de una historia intelectual en el marxismo del siglo XXI consiste en desplegar el concepto de "trabajo intelectual".

La sociedad del capital es la más intelectual de todas las sociedades complejas conocidas. No por la razón modernocéntrica de que las otras formas sociales sean más simples o inmediatas, sino porque la sociedad capitalista desarrolla un "intelecto general" (general intellect, escribe Marx en los cuadernos denominados Grundrisse) como aspecto de un automovimiento ciego de expansión. Por eso carece de sentido preguntarse cómo impactan la economía o la lucha de clases en la vida intelectual, como también por sus efectos en lo inconsciente o en la

3. Sorprenderá la ausencia en esta sección de las intuiciones de Antonio Gramsci sobre los intelectuales. El influjo del historicismo crociano tornó al marxismo gramsciano sensible al plano "espiritual". Sus apuntes sobre la vida intelectual fueron creativos y sutiles. Las funciones y distinciones de la cimentación intelectual de las relaciones entre las clases sociales generaron una frondosa bibliografia. Sin embargo, la aceptación del concepto de superestructura y la remisión del análisis a los fundamentos de clase suscitan problemas cuya discusión requeriría elaboraciones imposibles de desplegar aquí. 
teoría. Trabajo, representaciones y afectos, cosificación y generación de autonomías relativas, constituyen aspectos de una complejización social subordinada a la acumulación capitalista, que en modo alguno simplifica y suprime las diferencias: se alimenta de ellas como dimensiones de la multiplicación de ofertas mercantiles e instancias de densificación de la ganancia. Ciertamente puede ser investigada la relación entre recursos económicos o producción social y vida intelectual, o entre antagonismos de clase y representaciones culturales. Solo que es irrelevante para la propia teoría interrogarse dónde se encuentra un índice de eficacia mayor en el Leviatán capitalista.

El marxismo es, así, una teoría crítica de las prácticas mediadas en un todo alienado, si entendemos por esto el que se reproduce a sí mismo más allá de las intenciones de individuos, clases o élites. Como no hay un sujeto dentro de la máquina, la "sociedad" es contradictoria en numerosos planos, internos a los sectores de la producción e intercambio, a las relaciones entre las clases sociales, a los problemas sistemáticos de legitimación política, a la generación de prácticas intelectuales, entre otros. En contraste con la teoría, la historiografia introduce la interrogación de qué hacen los actores individuales y colectivos en sus contextos de tal manera condicionados; por eso mismo se pregunta por las metamorfosis de sus condicionamientos.

Desde el punto de vista de una reinterpretación del marxismo como teoría crítica de la sociedad, no se verifica una oposición con algunas premisas de la historia intelectual, tales como la autonomía relativa de las significaciones, la posibilidad de apropiaciones y fluencia de las representaciones, la complejidad de la cultura y sus diversidades glocalizadas. Para lo que aquí interesa, no obstante, es adecuado el señalamiento de Jürgen Habermas respecto de una devaluación en Marx de la interacción y las acciones comunicativas. Solo que en mi parecer esa es, paradójicamente, una dificultad y una virtud.

La crítica del valor involucra, en el análisis concreto de las prácticas del uso del lenguaje, la investigación de las mutaciones en las competencias discursivas debidas a la aceleración y multiplicación de la experiencia social. Pero el marxismo no es una teoría del lenguaje, la que no puede ser restringida en una clave historicista pues la facultad del lenguaje es transhistórica aunque sea afectada por los procesos históricos particulares. Lo mismo ocurre con fenómenos surgidos históricamente y devenidos en universales, tales como el monoteísmo, una cuestión crucial para la historia intelectual. El marxismo puede indagar cómo se interrelacionan las formas religiosas con la universalidad capitalista del dinero, pero debe renunciar a sostener la cifra de una explicación especulativa, si no desea enfrascarse en la desacreditada "filosofia de la historia". 
La rehabilitación del marxismo en la historia intelectual solo en parte puede comenzar en Lukács debido a su premisa romántica de una comunidad integrada luego fracturada por la racionalidad capitalista. Tal vez, con todo, se pueda rescatar del enfoque lukácsiano el libro de Lucien Goldmann, El dios oculto (1955), una lectura de la tragedia en Racine y Pascal. El estudio de Goldmann presupone un sistema de círculos concéntricos de determinación que alcanza una plasmación formal idónea, sostiene el autor, para comprender la peculiaridad histórica interna a las visiones del mundo del siglo XVII legibles en los escritos de Pascal y Racine. De tal manera, el círculo de la sociedad (1) y el círculo de las relaciones de clase (2), no se imponen mecánicamente sobre el tercer y más específico círculo de las obras concretas o, con mayor precisión, de su "estructura significativa" (3).

Un cuarto de siglo más tarde, el crítico literario Fredric Jameson tradujo el planteo de Goldmann en una imaginativa mixtura de Hegel, Althusser y Lacan en su obra El inconsciente politico (Jameson, 1981). Para Jameson, los círculos convergentes de historización remitían a los modos de producción (1), las luchas de clases (2) y los textos concretos (3) que procedía a examinar en su libro.

Una dificultad del enfoque compartido por Goldmann y Jameson consiste en que permanece supeditado al proyecto del marxismo como materialismo histórico. Jameson llega incluso a reinterpretar lo Real en Lacan como la Historia y ésta es conceptualizada como una teoría de los modos de producción, proyectando entonces a la "historia" características intransferibles de la sociedad capitalista. Al comprender la "sociedad" o el "modo de producción" como totalidades, los otros dos círculos de la conflictividad ideológica y de las obras se pliegan en una temporalidad única. Entonces están constreñidos a hacer ingresar con fórceps a sus lecturas todo aquello que remita a incertidumbres de determinación o temporalidades heterogéneas. Por el contrario, si una historiografia marxista es posible, incluida la intelectual, es siempre no-toda, coexiste con dimensiones irreductibles a la soberanía del capital. En consecuencia, a medida que el objeto de investigación se aleja del contexto capitalista, la utilidad del análisis marxista se reduce y exige convocar a teorías diferentes.

Otro inicio que deseo emplazar aquí concierne al proyecto teórico de Alfred Sohn-Rethel en su largamente meditado estudio Trabajo intelectual y trabajo manual, cuya versión final data de 1989. La elaboración de Sohn-Rethel comporta una crítica histórico-dialéctica de la epistemología kantiana. La teoría del conocimiento con la cual Kant se propuso fundamentar filosóficamente las condiciones de posibilidad de la ciencia newtoniana predicaba la ahistoricidad de las formas puras de la intuición sensible, de las categorias del entendimiento y en consecuencia 
de la facultad cognitiva del sujeto trascendental. Los rasgos ahistóricos del sujeto kantiano son, argumentó Sohn-Rethel, deshistorizaciones ideológicas de la subjetividad burguesa. La individualidad cognitiva del sujeto trascendental, supuestamente universal, corresponde con la forma-sujeto derivada de la generalización de la forma-mercancía. El individuo narcisista, la abstracción del tiempo lineal y del espacio continuo, la docena de categorias, son formas históricas y arbitrarias consagradas como trascendentales por la "filosofia crítica".

Sohn-Rethel provee los recursos elementales de un clivaje marxista en la historia intelectual. Una investigación de las prácticas intelectuales en el sistema burgués inscribe sus posibilidades y autonomías en el mundo ordenado por la valorización ampliada del capital. Insisto en que los planteos de Sohn-Rethel son elementales de una teoría crítica adecuada a una historia intelectual pues se requiere de un enorme trabajo filosófico e histórico para desplegarlo. En principio, se impone prolongar la crítica de la epistemología en una analítica histórica de las prácticas intelectuales (y no solo de ese tema más delimitado que es la "historia de las y los intelectuales"). De tal manera, se podría transitar de la "abstracción real" con que Sohn-Rethel sintetiza la generación de formas de pensamiento teórico en la cotidianidad mercantil burguesa, a una "abstracción social" verificada como precondición sistémica de las prácticas, incluidas las intelectuales. Finalmente, esa conexión fundamenta una vertiente crítica de lo intelectual como producto ambivalente de la producción capitalista de la realidad social.

Sin duda lo que viene de ser dicho a propósito de la teoría crítica parece ajeno al contexto intelectual argentino en el clima ideológico finisecular. No obstante, esta agenda encuentra un precedente local.

\section{Ante la crisis del marxismo}

A fines de la década de 1990, el filósofo e historiador intelectual José Sazbón propuso reconectar lo que por entonces estaba seccionado: la teoría crítica de raigambre marxista y la historia intelectual (Sazbón, 1997; un análisis en Garcia, 2011). La hipótesis de Sazbón era original y contaba con escasos antecedentes recientes, uno de los cuales podría ser el libro Socialismo fin-de-siècle de Martin Jay (1990).

La argumentación de Sazbón tenía dos goznes articuladores. En primer término, destacó retrospectivamente la relevancia de estudios generados desde la teoría crítica francfortiana para la nueva historia intelectual. En particular, resaltó la fertilidad de los análisis benjaminianos de la modernidad decimonónica en París y de los estudios habermasianos sobre las mutaciones de la esfera pública burguesa en el siglo XVIII. En segundo término, subrayó el interés emancipatorio 
de la teoría crítica usualmente licuado en la historiografia intelectual contenida en el afán reconstructivo. Es preciso subrayar, sin embargo, que la historia intelectual reciente no siempre puede ser remitida al arcón burocrático de una academia desinteresada por una teoría crítica. ${ }^{4}$

Sin rescindir la erudición documental y la rigurosidad conceptual, argumentó Sazbón, caracteriza a una posible contribución de la teoría crítica a la historia intelectual la "cita secreta" con los vencidos del pasado (Benjamin) o los supuestos normativos de una acción comunicativa exenta de distorsiones sistémicas (Habermas). La semilla de Sazbón cayó en terreno yermo mientras las antiguas y nuevas generaciones diagnosticaban un agotamiento irreversible del marxismo.

Los confines del siglo XX fueron aciagos para postular una sinergia entre teoria crítica (marxista) e historia intelectual. Una visita a la encuesta sobre "las ideas y sus historiadores" realizada por Alejandro y Fabián Herrero (1996) ilustra esa situación. Otro documento al respecto es el libro compilado por Elías Palti (n. 1956), con un título que también definía un campo problemático: Giro lingüístico e historia intelectual (1998). El trabajo de Palti se desplegaba a partir de la noción de una crisis de la representación, problemática alrededor de la cual organizó una recopilación de debates teóricos norteamericanos suscitados por el giro lingüístico en las humanidades. En ese momento dicha crisis, derivada de la emergencia de la relatividad, señalaba el autor, era compartida por el arte y la historia intelectual. Los escritos posteriores de Palti mantuvieron la premisa de una crisis de la representación, reorientada a la representación política. Su enigma fue y es la crisis del marxismo, aunque luego la situara en el contexto más dilatado de un desfondamiento de "lo político".

En el trabajo de 1998 la situación crítica se despliega en la asunción del giro lingüístico -definido en términos de "los modos de producción, apropiación y circulación de los sentidos" (1998, p. 20, n. 5)- como otra cosa que la resolución de la mencionada situación. De allí que el giro

4. Russell Jacoby (1992) lo planteó de esa manera en una acerba impugnación de las perspectivas de Hayden White y Dominick LaCapra. Como señaló el propio LaCapra en su respuesta, Jacoby cuestionaba a la nueva historia intelectual en el contexto de su enérgico enjuiciamiento de la domesticación de los intelectuales en los Estados Unidos. El formalismo de White y el textualismo de LaCapra expresarian matices de una renuncia a cuestionar la sociedad contemporánea. Es impracticable desplegar aquí un examen del planteo de Jacoby. Lo cierto es que la réplica de LaCapra (1992), y en verdad gran parte de su obra, no suponen la renuncia a una teoría crítica. Por el contrario, sus estudios plantean explícitamente la reconstrucción de una teoría crítica en la cual el marxismo es más un objeto de análisis que un insumo analítico. Al menos tres de sus libros portan "teoría crítica" en sus títulos (LaCapra, 1989, 2004 y 2013), donde el historiador intelectual procura un diálogo entre Marx, Freud y Derrida. 
"lingüístico" no pudiera asimilarse con el giro "interpretativo". Su eficacia involucraba la caída de toda promesa hermenéutica.

El carácter "intelectual" de la historiografia propuesta por Palti no obedece a su objeto (intelectuales, discursos, pensamientos, etcétera), sino a una autorreflexión historiadora en términos teórico-políticos. Así ocurre con el itinerario construido de programas interpretativos desde el seminal ensayo de Skinner sobre la historia de las ideas publicado en 1969, las incertidumbres del contextualismo que transita de la intencionalidad a la legibilidad epocal, es decir, a una disolución del texto como documento en beneficio de una metacrítica de la producción en el ámbito del saber humanístico. En ese preciso lugar se concentra la diferencia con la historia de las ideas que, como señalé a propósito del Journal of the History of Ideas, se restringia a su especialidad. La historia intelectual detenta otra ambición: la de evidenciar que toda historiografia es historia intelectual.

El planteo de Palti halla también "puntos ciegos" en un linguistic turn que en sus diversas variantes socava sus propias justificaciones racionales al verse constreñido a incorporar sucesivos niveles reflexivos (de la lingüisticidad de los objetos estudiados a la de la recepción de sus resultados y, luego de dicha recepción a las condiciones de producción académica, y asi hasta el infinito). De tal manera, ni la tropología en Hayden White, ni la historia marxisto-lacaniana en Fredric Jameson se autoexplican. Requieren de instancias metateóricas que no pueden ser también tropológicas o marxisto-lacanianas, pues su tautología reenviaría a nuevos planos meta-metateóricos. El lenguaje, cualquiera sea la teoría lingüística utilizada, no es un nuevo fundamento. Ya entonces, "una dimensión de las prácticas sociales que trascienden la instancia textual" (Palti, 1998, p. 166) proveía el contrapunto de las construcciones de lenguaje que el autor no soñaba evadir.

Desde entonces Palti desarrolló una obra vasta y de primera importancia en la historia intelectual latinoamericana. Textos como Verdades y saberes del marxismo (2005) y Una arqueología de lo politico (2018), son de lectura recomendable para cualquier público lector interesado en una reflexión sobre la teoría crítica en el inicio del siglo XXI. Para el objeto del presente trabajo, su enfoque postmarxista, orientado a la detección de aporias constitutivas que erosionan las premisas en que se sostiene un régimen discursivo, requiere mayores mediaciones.

El trabajo reciente de Palti retoma el esquema de Foucault en Las palabras y las cosas transfiriendo el análisis de lo epistémico a lo político y añadiendo una nueva fase, la de disolución de las categorías histórico-filosóficas sustantivizadas descriptas por Koselleck para el Sattelzeit de acceso a la modernidad. Matrices simbólicas autónomas -aunque socavadas por la relación a la larga insostenible entre inmanencia y 
trascendencia en que se funda lo politico- constituyen las precondiciones de la periodización.

Palti asume una definición imposible de ser admitida sin una teorización poshistórica y postpolítica de la historia: la obsolescencia de lo político del siglo evolucionista y teleológico que fue el XIX y el pragmático y subjetivista que fue el siglo XX. El historiador intelectual lee su época desde un agotamiento que no genera su propia superación. Entonces, si bien Foucault le permite segmentar épocas de discutible validez general, es Derrida y su deconstrucción quien provee al historiador argentino del último refugio metódico ante el derrumbe definitivo del marxismo: el gesto interminable de una promesa caída, la sombra de un fantasma destinado a desconocer su propia obsolescencia. Incluso la tragedia que si no habilita transformar el mundo al menos admite inteligirlo lúcidamente, ha perimido. Nuestra contemporaneidad sería postrágica. El horizonte conceptual de Marx, ese lector apasionado de Shakespeare, se ha disuelto. He alli el argumento de un dificil diálogo del pensamiento de Palti con la investigación marxista. No obstante, pienso que si algunos posmarxismos participan de una historia del marxismo (tesis que es inviable explicar aquí), la historia intelectual arqueológico-deconstructiva de Palti es uno de ellos. Una de las enseñanzas de la historia intelectual es que los autores son súbditos de las significaciones de sus discursos.

\section{La historia intelectual en términos de "recepción" y la historia social}

El antes citado ensayo de Sazbón no refuta el diagnóstico general con que comenzó el presente artículo. Pero matiza una circunstancia argentina en la que el marxismo, ciertamente disminuido, tuvo una exilar sobrevida. Así las cosas, cuando Carlos Altamirano preparó un breviario sobre los estudios de "los intelectuales", en contraste con el silencio del libro de Dosse, dedicó un capítulo al análisis marxista. Interesa menos que Altamirano resolviera el tema con referencia a la producción ideológica según La ideología alemana y la distinción gramsciana entre intelectuales orgánicos y tradicionales, que el hecho mismo de que tal enfoque mereciera siquiera una esquemática presentación (Altamirano, 2006, pp. 49-68).

En esta circunstancia, es menos sorprendente el perfil del historiador Horacio Tarcus (n. 1955), una referencia insoslayable en el presente análisis. El pensamiento histórico de Tarcus admite ser filiado en el trabajo de Goldmann tal como es reconstituido por su discípulo Michael Löwy. Esto es significativo porque Tarcus retoma de Lukács y Goldmann el recurso a la "visión trágica" para estudiar las trayectorias de Milciades Peña y Silvio Frondizi (Tarcus, 1996). ¿Qué supone la sensibilidad hacia lo trágico sino la apuesta por reactivar la promesa marxista tras la crisis 
del marxismo? Otro antecedente proviene de los estudios de José Aricó sobre el socialismo argentino de Juan B. Justo, en los cuales el autor de Marx y América Latina defiende, contra el revisionismo histórico de izquierda, su comprensión mejor en términos de un programa politico y teórico suscitado por una evaluación perspicaz de la sociedad argentina. Más adelante, Tarcus halló en las elaboraciones de la "estética de la recepción" algunos procedimientos metodológicos para operacionalizar sus investigaciones sobre la circulación del socialismo romántico y del marxismo en la Argentina. Ese desplazamiento metodológico se efectuó sin desarrollar el trasfondo de historia social subyacente en los enfoques -no en la práctica efectiva- de Aricó, cuyos estudios Tarcus (2020a) transfigura retrospectivamente en la clave de la "recepción".

En una discusión significativa, Aricó (1982) reprocha a la antología de Löwy, El marxismo en América Latina, imponer un preconcepto de homogeneidad ideológica en sus clasificaciones (marxismos reformista, revolucionario, cientificista, etcétera) allanando las complejidades y mezclas, además de introducir una normativa arbitraria en el análisis histórico. El crítico, por su parte, proyecta estudiar el socialismo argentino del 1900 como expresión de la propia sociedad local y no como una "idea extranjerizante", desplazando en consecuencia la pregunta por la originalidad de una teoría respecto de su existencia histórica. Los trabajos de Aricó sobre Mariátegui compartieron la misma premisa.

Habilitar una investigación marxista sobre el marxismo en América Latina exige, para Aricó, abandonar la causación económica de la política presente desde Marx. La relación "invertida" entre política y economía es útil para evaluar la capacidad "productiva" del Estado en América Latina. Retomando una sugerencia de Terán, Aricó se empeña en repensar un "marxismo de puntos de fuga", dispersivo, no hegeliano, si entendemos por ello la afirmación de una totalidad absoluta. Para habilitar la historia del marxismo local -aunque la estipulación era válida para cualquier empresa historiográfica en clave marxista- se requiere cuestionar el uso del concepto de "modo de producción" como equivalente de realidad social. Ese concepto revisado, sin embargo, no podía ser simplemente descartado. Aricó incluso menciona el libro de Habermas de 1976 para convalidar el proyecto de una "reconstrucción del materialismo histórico".

Perteneciente a otra generación, el enfoque de Tarcus presente en sus trabajos sobre Peña y Frondizi de la década de 1990 no renuncia a los "intelectuales faro", aunque procura "repensarlos dentro de tramas político-culturales más vastas" (Tarcus, 2015: 15). Como ya indiqué, Tarcus dialoga con El dios oculto de Goldmann. Mas en lugar de interrogar los regimenes de derivación entre la sociedad, las clases y los textos, adopta la vía de Löwy de reconstruir itinerarios biográficos de 
un marxismo con los que el propio Tarcus se identifica, caracterizado por vocablos tales como heterodoxo, no dogmático, abierto, cálido, herético, trágico... En un largo epílogo reciente a su investigación sobre el socialismo romántico en el Río de la Plata, Tarcus (2020b: 255-325) complementa las reconstrucciones de biografias político-intelectuales con un análisis próximo a la historia conceptual.

La apelación al tema de la "recepción" y de la "lectura", que no es inexorable filiar en el marxismo, permite despejar problemas imaginarios suscitados por inquisiciones desencaminadas tales como la de si Esteban Echeverría leyó correctamente a Pierre Leroux y Juan B. Justo a Marx, o la de si tal o cual actor hizo un uso inadecuado, empobrecedor o preciso del marxismo.

La obra de Tarcus en varios volúmenes sobre la recepción del socialismo romántico y sobre las primeras lecturas de Marx en la Argentina modifica la cronología de la historia del socialismo y del marxismo locales. También lo introduce en el seno de una historia de la cultura con alcance transnacional. No es seguro que su enfoque involucre dimensiones de una historia social y política, aunque proporciona elementos esenciales para preguntas marxistas, tales como las de una historia global de la circulación de saberes y programas sociopolíticos radicalizados, las condiciones que para esa circulación supone la incorporación plena de la Argentina al mercado mundial, la constitución de un denso sistema de clases sociales, la aparición de partidos políticos de izquierda, la expansión de lo público y los medios masivos de comunicación, entre muchos otros temas relevantes para enriquecer la historia intelectual.

Una agenda del programa de una historia intelectual en términos de recepción, coexistente con su riqueza descriptiva, involucra desarrollar una vinculación no reduccionista con la historia social. En la medida en que los usos se combinan en circuitos y préstamos heterogéneos, la historia intelectual se revela como un aporte conducente a desbordarse hacia una más amplia historia social y cultural, excediendo la delimitación de lo intelectual a las élites letradas, según proclamó hace algún tiempo Jonathan Rose en su libro La vida intelectual de las clases trabajadoras, o elaboró Jacques Rancière en La noche de los proletarios. En otras palabras, una historia intelectual "desde abajo" es una deuda pendiente, que tiene la virtud de reponer el dilema de la historia intelectual respecto de lo social.

Sucede que si la reseña de Garavaglia fue injusta con el libro de Myers, no carecía de alguna razón cuando reclamaba una mayor densidad metodológica, pues las especializaciones historiográficas constituyen recortes analíticos de realidades complejas. Para la pregunta sobre el marxismo, una delimitación al análisis de las prácticas discursivas -que en modo alguno es solo textualista pues involucra, como se lee en las 
últimas indagaciones de Tarcus, diversas realidades asociadas tales como el periodismo, los exilios, los intercambios epistolares, etcéteraentraña la interrogación de su relación con el despliegue del intelecto general de las formas concretas asumidas por el orden capitalista. ${ }^{5}$

\section{Conclusiones}

Este artículo ha provisto un panorama sinóptico y orientado a su objeto de la evolución de la historia intelectual, según se la advierte en las peripecias de la universidad argentina que siguió a la transición democrática. También ha sintetizado la reinterpretación de la teoría crítica en términos de una hermenéutica dialéctico-negativa de la sociedad capitalista, en la que conceptos como trabajo intelectual y general intellect plantean la viabilidad -por el momento esquemática- de una historia intelectual internamente conectada con la critica marxista.

En el ámbito de la historia intelectual, un proyecto marxista apoyado en una reinterpretación de la teoría crítica puede desplegarse nutriéndose de antecedentes como los de Aricó y en parte los de Terán, aunque más consistentemente en las sugerencias metódicas de Sazbón. Respecto de elaboraciones recientes, los estudios de historia intelectual de Palti son relevantes para lo que podría denominarse una historia social de las prácticas intelectuales tras la crisis del marxismo. Las investigaciones de Tarcus exigen menos reinterpretaciones marxistas, naturalmente, que el posmarxismo de Palti. Dichos desarrollos suscitan la viabilidad de expandir su alcance más allá de las élites intelectuales y sus arrabales de izquierda para incorporar un debate sobre las peripecias de la cultura y, más exactamente, del quehacer intelectual, con una apertura enriquecida que se suele identificar con los escritos de Gramsci.

La singularidad de una aproximación, en la línea de la teoría crítica invocada en la Argentina por Sazbón, no se limita a proporcionar una variante marxista en el abanico plural de la historia intelectual. Procura desplegar las potencias analíticas y transformadoras de una investigación rigurosa como cualquier otra, pero atizada por la injusticia social, emocional y cultural inherente a la totalidad enajenada. Ese es el filo de la teoría crítica marxista, que por desgracia ningún posmarxismo ha podido aún suplantar, y cuyas promesas analíticas (pues las políticas obedecen a otra estructuración de las prácticas) este escrito quiso contribuir a plantear.

5. La presencia de los escritos de Palti y Tarcus en este artículo sugeriría la conveniencia de un examen de su debate a propósito de la relación entre historia y tragedia. Las interferencias ad hominem en dicha polémica malogran su utilidad para el espacio disponible. 
Una historia intelectual de raigambre marxista es aún un proyecto, incluso si por razones señaladas debe ser no-toda. Mientras perdure la dominación ambivalente del orden capitalista puede contribuir a elucidar uno de sus aspectos productivos más eficaces, a saber, la apropiación del intelecto general por el capital. Pero también todo aquello que en las experiencias de los actores excede a esa apropiación y demanda una detallada investigación documental.

Por sobre todas las cosas, un sesgo marxista en la historia intelectual desmitifica el prestigio de lo intelectual como tal para revelar su contracara en la dominación y desprecio del "trabajo manual". La teoría crítica excede un enfoque meramente represivo en la relación social capitalista. La sociedad capitalista multiplica las dimensiones intelectuales de las prácticas en su apetito de ganancia. Esa faceta productiva se despliega en una historia social de las prácticas intelectuales. La coligación entre diversas lógicas de abstracción conduce a una subdeterminación del quehacer intelectual por la lógica del capital, pues la abstracción social convive con otras abstracciones de historicidades diferentes. El reconocimiento de ese límite para la vigencia del marxismo en la historia intelectual no va en su detrimento. Desde Kant, un rasgo esencial de la teoría crítica consiste en la reflexividad sobre sus propias limitaciones.

\section{Bibliografía}

Acha, O. (2017), Cambiar de ideas. Cuatro tentativas sobre Oscar Terán, Prometeo Libros.

Altamirano, C. (1990-1991). Breve apología de la historia intelectual. Espacios de Crítica y Producción, 8-9, 3-5.

Altamirano, C. (2006). Intelectuales. Notas de investigación. Norma.

Aricó, J. (1982). Disquisiciones en torno a un concepto problemático. En Nación, estado e ideología en las formaciones precapitalistas. Ponencias (pp. 25-44). Instituto Nacional de Antropologia e Historia.

Dosse, F. (2007). La marcha de las ideas. Historia de los intelectuales, historia intelectual. Universitat de València.

Garavaglia, J.C. (1996). Discursos, textos y contexto. Breves reflexiones acerca de un libro reciente. Estudios Sociales, Revista Universitaria Semestral, 6 (10), 221-227. https://doi.org/10.14409/es.v10i1.2359

García, L.I. (2011). Teoría crítica e historia intelectual en José Sazbón, Politicas de la Memoria, 10-11-12, 275-282.

Goldmann, L. (1955). Le dieu caché. Étude sur la vision tragique dans les Pensées de Pascal et dans le théâtre de Racine. Gallimard (trad. cast. El dios oculto. Planeta-Agostini, 1986).

Higham, J. (1951). The Rise of American Intellectual History, American Historical Review, 56 (3), 453-471. https://doi.org/10.2307/ 1848432

Herrero, A. y F. Herrero (1996). Las ideas y sus historiadores. Un fragmen- 
to del campo intelectual en los años noventa. Universidad Nacional del Litoral.

Jacoby, R. (1992). A New Intellectual History? American Historical Review, 97, 405-424. https://doi.org/10.1086/ahr/97.2.405

Jameson, F. (1981). The Political Unconscious. Narrative as a Socially Symbolic Act. Routledge (trad. cast. Documentos de cultura, documentos de barbarie. Visor, 1989).

Jay, M. (1990). Socialismo fin-de-siècle y otros ensayos. Nueva Visión.

LaCapra, D. (1989). Soundings in Critical Theory. Cornell University Press.

LaCapra, D. (1992). Intellectual History and Its Ways. American Historical Review, 97, 425-439. https://doi.org/10.2307/2165726

LaCapra, D. (2004). History in Transit: Experience, Identity, Critical Theory. Cornell University Press (trad. cast., Historia en tránsito, Fondo de Cultura Económica, 2006).

LaCapra, D. (2013). History, Literature, Critical Theory. Cornell University Press.

LaCapra, D. y S. Kaplan (eds.) (1982). Modern European Intellectual History. Reappraisals and New Perspectives. Cornell University Press.

Lovejoy, A. (1940). Reflections on the History of Ideas, Journal of the History of Ideas, 1, 3-23, DOI: 10.2307/2707007. [Trad. cast., Reflexiones sobre la historia de las ideas, Prismas, 4 (2), 127-141.]

Myers, J. (1995). Orden y virtud. El discurso republicano en el régimen rosista. Universidad Nacional de Quilmes.

Myers, J. (1996). Comentarios a una reseña reciente. Estudios Sociales, Revista Universitaria Semestral, 6 (11), 181-186.

Palti, E.J. (ed.) (1998). Giro lingüístico e historia intelectual. Universidad Nacional de Quilmes.

Palti, E.J. (2005). Verdades y saberes del marxismo. Reacciones de una tradición política ante su "crisis". Fondo de Cultura Económica.

Palti, E.J. (2018). Una arqueología de lo politico. Fondo de Cultura Económica.

Roig, A. (1990). Tres décadas de historia de las ideas: recuento y balance. En AA.VV., Historiografía argentina (1958-1988). Una evaluación critica de la producción histórica argentina (pp. 535-548). Comité Internacional de Ciencias Históricas.

Sabato, H. (1986). La historia intelectual y sus limites. Punto de Vista, año IX, 28, 27-31.

Sazbón, J. (1997). Historia intelectual y teoría crítica. Páginas de Filosofía, 4 (6), 29-42 (incorporado a su Nietzsche en Francia y otros estudios de historia intelectual, Universidad Nacional de Quilmes, 2009).

Sohn-Rethel, A. (1989). Geistige und kôrperliche Arbeit. Zur Epistemologie der abendländische Geschichte. AVC/Acta Humaniora (trad. cast. de una edición previa: Trabajo intelectual y trabajo manual. El Viejo Topo, 1980).

Tarcus, H. (1996). El marxismo olvidado en la Argentina. Silvio Frondizi y Milcíades Peña. El Cielo por Asalto. 
Tarcus, H. (2007). Marx en la Argentina. Sus primeros lectores obreros, intelectuales y cientificos. Siglo Veintiuno.

Tarcus, H. (2015). Una invitación a la historia intelectual: palabras de apertura del II Congreso de Historia Intelectual de América Latina. Revista Pléyade, 15, 9-25.

Tarcus, H. (2016). El socialismo romántico en el Río de la Plata (1837-1852). Fondo de Cultura Económica.

Tarcus, H. (2020a). José Aricó y la historia del marxismo en América Latina: la historia intelectual y la perspectiva de la recepción. Politicas de la Memoria, 20, 146-155. https://doi.org/10.47195/20.657

Tarcus, H. (2020b). Los exiliados románticos. Socialistas y masones en la formación de la Argentina moderna, 1853-1880. Fondo de Cultura Económica.

Terán, O. (1991). Nuestros años sesentas. La formación de la nueva izquierda intelectual argentina, 1956-1966. Puntosur. 